\title{
REFLEXÕES SOBRE O PNLD - ALFABETIZAÇÃO NA IDADE CERTA (2013): LITERATURA NAS SALAS DE ALFABETIZAÇÃO
}

\author{
Claudia Leite Brandão ${ }^{1}$ \\ Renata Junqueira de Souza ${ }^{2}$
}

Resumo: A promoção do acesso a diferentes obras literárias é necessária em qualquer fase educacional; no entanto, não podemos negar que desde o início do processo de alfabetização/letramento é imprescindível a presença dos livros para a inserção das crianças na cultura grafocêntrica. Nesta perspectiva, o Ministério da Educação (MEC), no ano de 2013, iniciou as ações do Pacto Nacional pela Alfabetização na Idade Certa (PNAIC), que apontava como meta alfabetizar as crianças até 8 anos de idade; com esse Programa também foi iniciada a distribuição de livros de literatura infantil por meio do PNLD-Alfabetização na Idade Certa (PNLD-PNAIC). Diante disso, este estudo objetiva compreender as ações do PNLD-PNAIC a partir de reflexões sobre a importância da presença da literatura nas salas de alfabetização. Para tanto, esta investigação consiste em uma pesquisa de abordagem quanti-quali, de cunho documental e bibliográfico, tendo como instrumento a análise de documentos oficiais, dentre outras publicações relacionadas ao Programa dispostos no portal do Ministério da Educação e Fundo Nacional de Desenvolvimento da Educação (FNDE). Esperamos que esse texto contribua para que os profissionais da educação (professores, gestores, bibliotecários e pesquisadores) conheçam as ações do PNLD-PNAIC e, a partir disso, se interessem por mediar a circulação das obras na escola.

Palavras-chave: Educação; Literatura infantil; Educação do leitor; Programa nacional de incentivo à leitura.

\footnotetext{
1 Doutora em Educação na Universidade Estadual Paulista Júlio Mesquita Filho. Mestre em Educação, na Linha de Pesquisa Linguagens, Cultura e Construção do Conhecimento, na Universidade Federal de Mato Grosso (PPGEdu/CUR/UFMT). Professora da Educação Básica na rede estadual de ensino no Estado de Mato Grosso. Emai: cau_brandao@live.com

2 Doutora em Letras pela Universidade Estadual Paulista Júlio de Mesquita Filho (2000), Mestre em Linguística e Letras pela Pontifícia Universidade Católica do Rio Grande do Sul (1990), pós-doutorado pela University of British Columbia (2001) e pela Ohio State University (2005). Livre-docente na Universidade Estadual Paulista Júlio de Mesquita Filho, professora visitante da Universidade do Minho e Coordenadora do Centro de Estudos em Leitura e Literatura Infantil e Juvenil (CELLIJ). E-mail: recellij@gmail.com
} 


\title{
REFLECTIONS ON THE PNLD - LITERACY IN IDADE CERTA (2013): LITERATURE IN THE LITERACY CLASSROOMS
}

\begin{abstract}
The promotion of access to different literary works is necessary in any educational phase, however we cannot deny that from the beginning of the literacy process it is indispensable the presence of books for the insertion of children in the grafocentric culture. In this perspective, the Ministry of Education (MEC), in 2013, initiated the actions of the Pacto Nacional pela Alfabetização na Idade Certa (PNAIC), which aimed to literate children up to 8 years old; with this Program the distribution of children's literature books through PNLD-Literacy in the Idade Certa (PNLD-PNAIC) also started. Therefore, this study aims to understand the actions of the PNLD-PNAIC from reflections on the importance of the presence of literature in the literacy classes. To do so, this research consists of a quali-quantitative approach, with a documental and bibliographical approach, having as an instrument the analysis of official documents, among other publications related to the Program arranged in the portal of the Ministry of Education and the National Fund for Development of Education (FNDE). We hope this text will help educators (teachers, managers, librarians and researchers) to know the actions of the PNLD-PNAIC and, from this, get interested in mediating the circulation of the works in the school.
\end{abstract}

Keywords: Education. Children's Literature. Education of the reader. National program to encourage reading.

\section{REFLEXIONES SOBRE EL PNLD - ALFABETIZACIÓN EN LA IDADE CERTA (2013): LITERATURA EN LAS SALAS DE ALFABETIZACIÓN}

Resumen: La promoción del acceso a diferentes obras literarias es necesaria en cualquier fase educativa; sin embargo, no podemos negar que desde el inicio del proceso de alfabetización/literacidad es imprescindible la presencia de los libros para la inserción de los niños en la cultura grafocéntrica. En esta perspectiva, el Ministerio de Educación (MEC), en 2013, inició las acciones del Pacto Nacional pela Alfabetização na Idade Certa (PNAIC), que apuntaba como meta alfabetizar a los niños hasta 8 años de edad; con ese Programa también se inició la distribución de libros de literatura infantil a través del PNLD- Alfabetização na Idade Certa (PNLD-PNAIC). En este estudio se pretende comprender las acciones del PNLD-PNAIC a partir de reflexiones sobre la importancia de la presencia de la literatura en las salas de alfabetización. Por lo tanto, este trabajo consiste en una investigación de abordaje cuantitativo y cualitativo, de cuño documental y bibliográfico, teniendo como instrumento el análisis de documentos oficiales, entre otras publicaciones relacionadas al Programa dispuestos en el portal del Ministerio de Educación y el Fondo Nacional de Desarrollo de la Educación (FNDE). En el caso de los profesores, gestores, bibliotecarios e investigadores, que ellos conozcan las acciones del PNLD-PNAIC y, a partir de eso, se interesen por mediar la circulación de las obras en la escuela.

$\begin{array}{lccrrr}\text { Palabras clave: Educación. } & \text { Literatura } & \text { Infantil. } & \text { Formación de Lectores. } \\ \text { Programas } & \text { de } & \text { Incentivo } & a & \text { la } & \text { lectura. }\end{array}$ 


\section{Palavras iniciais}

O encontro da criança com os livros abre o mundo da língua escrita, ou seja, de uma outra linguagem. À riqueza da língua oral se acrescenta a da língua escrita que, por sua vez, vai participar da educação da pessoa em todas as suas dimensões, imaginária, científica, cívica, mas também linguageira e cognitiva. (BAJARD, 2014, p. 43).

A promoção do acesso a diferentes obras literárias é necessária em qualquer fase educacional, no entanto, não podemos negar que desde o início do processo de alfabetização/letramento é imprescindivel a presença dos livros para a inserção das crianças na cultura grafocêntrica. Conforme Rocha e Machado (2011, p. 38-39):

Um grande desafio para nós todos, como projeto de país e como numa nação democrática, consiste em dar a todos, sem exceção, a chance de saber que a leitura de literatura existe e a garantia de oportunidade para que cada um possa descobrir nas bibliotecas públicas os livros de que poderá gostar, em meio a uma oferta grande e variada.

Nesta perspectiva, o Ministério da Educação (MEC), no ano de 2013, iniciou as ações do Pacto Nacional pela Alfabetização na Idade Certa (PNAIC), que apontava como meta alfabetizar as crianças até 8 anos de idade. Com esse Programa também foi iniciado a distribuição de livros de literatura infantil por meio do PNLD-Alfabetização na Idade Certa (PNLDPNAIC).

Em relação ao desenvolvimento do Programa Souza, Silva e Ariosi (2016) destacaram que os principais objetivos e dinâmica dos encontros eram: conhecer os recursos didáticos (livros e jogos) distribuídos pelo MEC; planejar a alfabetização partindo de uma rotina com a perspectiva no letramento; compreender a importância da literatura; esquematizar as situações que promovessem o uso das obras do Programa Nacional Biblioteca da escola (PNBE), PNLD - Obras Complementares e do PNLDPNAIC.

A formação do PNAIC se estruturou em princípios teóricosmetodológicos, pois, a partir dos estudos de textos referenciais, elaborava-se atividades para, posteriormente, as alfabetizadoras aplicarem em sala de aula. Assim, após o desenvolvimento das 
atividades, as professoras cursistas compartilhavam os resultados nos encontros, trocando experiências e refletindo sobre suas experiências. Nessa direção, as principais propostas do PNAIC eram:

[...] leitura deleite, tarefas de casa e escola e retomada do encontro anterior, estudo dirigido de textos, planejamento de atividades a serem realizadas nas aulas seguintes ao encontro, socialização de memórias, vídeo em debate, análise de situações de sala de aula filmadas ou registradas, análise de atividades de alunos, análise de relatos de rotinas, sequências didáticas, projetos didáticos e de planejamentos de aulas, análise de recursos didáticos, exposição dialogada, elaboração de instrumentos de avaliação e discussão de seus resultados e, finalmente, avaliação da formação. (SOUZA; SILVA; ARIOSI, 2016, p. 71).

Diante disso, este estudo objetiva compreender as ações do PNLDPNAIC a partir de reflexões sobre a importância da presença da literatura nas salas de alfabetização. Corroborando com Arena (2010, p. 15) quando afirma que "a literatura medeia a relação da criança com a cultura de sua época, mas transcende a ela, tanto para o passado, quanto para o futuro". Desse modo, apresentamos este texto como subsídio aos profissionais da educação (professores, gestores, bibliotecários e pesquisadores) para que conheçam as ações do PNLDPNAIC e a partir disso, se interessem por mediar a circulação das obras na escola.

Nesta direção, esta investigação consistiu em uma pesquisa de abordagem quanti-quali, de cunho documental e bibliográfico, tendo como instrumento a análise de documentos oficiais, dentre outras publicações relacionadas ao Programa dispostos no portal do Ministério da Educação e Fundo Nacional de Desenvolvimento da Educação (FNDE).

\section{Hora de Compreender as Ações do PNLD-PNAIC 2013}

Por meio de uma ação conjunta entre o Pacto Nacional pela Alfabetização na Idade Certa e o Programa Nacional do Livro Didático (PNLD), no ano de 2013, foram distribuídos os acervos nomeados como PNLD - Alfabetização na Idade Certa, os livros tinham a finalidade de auxiliar o processo de introdução das crianças à cultura da escrita e leitura. Na concepção de Silva, 
[...] se quisermos formar comunidades de leitores e motivar as crianças a aprender como se escreve, precisamos não perder de vista a necessidade de garantir tempo pedagógico para leitura de textos literários (leitura deleite), leitura de diversos gêneros textuais em jornais, revistas, entre outros portadores, e participação em situações em que elas irão interagir com outras pessoas através da escrita. (SILVA, 2005, p. 145).

Nesta perspectiva, os livros do PNLD - PNAIC foram distribuídos para serem dispostos nas salas do $1^{\circ}$ ao $3^{\circ}$ ano do Ensino Fundamental, a fim de que a literatura mantivesse a presença contínua nas práticas de leitura.

Para Soares (2010, p. 15-16), “a literatura torna o mundo e a vida compreensiveis, porque revela outros mundos e outras vidas [...], a leitura literária possibilita o acesso da criança ao rico acervo de contos de fadas, de fábulas, de poemas que fazem parte da cultura de nossas sociedades".

Dessa forma, no ano de 2013, houve a aquisição de setenta e cinco (75) obras literárias, que foram divididas para compor três acervos, com vinte e cinco (25) títulos. Sobre a escolha dos livros Paiva e Corrêa (2015) informaram que não houve um edital específico para a aquisição das obras do PNLD - PNAIC 2013, os títulos foram selecionados a partir dos acervos do PNBE 2012.

Vale informar que a edição do Programa Nacional Biblioteca da Escola 2012 distribuiu livros de literatura para a Educação Infantil (creche e pré-escola), Ensino Fundamental - anos iniciais e Educação de Jovens e Adultos. A partir destas informações, realizamos um levantamento dos títulos selecionados para o PNBE 2012 e PNLD PNAIC 2013, com o intuito de compreender a composição dos acervos distribuídos para as escolas. O Quadro 1 demonstra o quantitativo de títulos do PNBE 2012 que fizeram parte da composição do PNLD PNAIC 2013.

Quadro 1. Total de títulos do PNBE 2012 selecionados para PNLD - PNAIC 2013 
Brandão, C.L.; Souza, R. J.

\begin{tabular}{|c|c|c|}
\hline $\begin{array}{c}\text { Programa e Modalidade de } \\
\text { Atendimento }\end{array}$ & $\begin{array}{l}\text { Quantidades de } \\
\text { livros adquiridos }\end{array}$ & $\begin{array}{c}\text { Quantidades de } \\
\text { livros do PNBE } \\
2012 \text { selecionados } \\
\text { para PNLD - PNAIC } \\
2013 \\
\end{array}$ \\
\hline PNBE 2012 / Creche & 50 & 18 \\
\hline PNBE 2012 / Pré-escola & 50 & 20 \\
\hline PNBE 2012 /Anos Iniciais - E.F & 100 & 36 \\
\hline $\begin{array}{c}\text { PNBE 2012 / Educação de Jovens } \\
\text { e Adultos }\end{array}$ & 50 & 01 \\
\hline TOTAL & 250 & 75 \\
\hline
\end{tabular}

Fonte: Elaborado com dados de Brasil (2016a, 2016b)

Diante dos dados levantados, avaliamos que para a composição do PNLD - PNAIC 2013 das setenta e cinco (75) obras, 48\% foram selecionadas do acervo direcionado para os anos iniciais do Ensino Fundamental, 27\% da pré-escola, 24\% da creche e 1\% do EJA. Se os livros do PNLD - PNAIC 2013 foram selecionados a partir do PNBE 2012, podemos afirmar que as obras contemplaram diferentes gêneros literários: a) prosa: quadra, parlenda, cantiga, trava-lingua, poema, adivinha; b) versos: clássicos da literatura infantil, pequenas narrativas, textos de tradição popular, fábulas, lendas e mitos, livros de imagem e histórias em quadrinhos, c) Livros ilustrados e/ou livros de imagens.

Sobre a diversidade de gêneros literários nas escolas, Soares (2010, p. 15) assegura que o processo de alfabetizar letrando "desenvolve-se no contexto de uma vivência intensa e diversificada, pela criança, dos usos e práticas sociais da língua escrita, o que significa interagir com materiais reais de leitura e escrita: textos de diferentes gêneros e diferentes suportes, textos para ler."

Ainda analisando os dados de aquisição do PNLD - PNAIC 2013, ressaltamos que foram adquiridos uma tiragem de 143.061 de cada título selecionado, totalizando uma compra de 10.729.575 exemplares, para compor 427.155 acervos que foram entregues a 109.466 escolas, com um investimento final de $\mathrm{R} \$ 38.251 .650,18$. Por conta desses números, não há dúvida de que a compra dos livros pelo Governo Federal movimenta o mercado editorial. Avaliando os valores percebemos que 
Brandão, C.L.; Souza, R. J.

para aquisição dos 75 títulos foram gastos o valor de $R \$ 267,38$. Isso pressupõe uma média de custo de $\mathrm{R} \$ 3,56$ para cada obra adquirida.

Na compra do PNLD - PNAIC 2013, o Governo Federal negociou com cinquenta e duas (52) editoras que venderam de 1 a 3 títulos para a composição dos acervos. Entre as editoras com mais livros selecionados estão a Cosaf \& Naif Edições LTDA totalizando uma negociação de $\mathrm{R} \$ 1.702 .425,90$ correspondendo a 4,45\% do valor investido pelo Programa e a Brinque Book Editora de Livros com a venda final de $\mathrm{R} \$ 1.606 .575,03$ sendo 4,20\% do total de venda ao PNLD-PNAIC.

Nas palavras de Brandão (2016), as compras de livros pelo Governo Federal provocaram uma movimentação editorial, visto que os programas governamentais são responsáveis por uma média de $40 \%$ do faturamento anual das editoras. O Quadro 2 apresenta as editoras das obras do PNLD-PNAIC 2013.

Quadro 2. Editoras selecionadas para o PNLD-PNAIC 2013

\begin{tabular}{|c|l|c|c|c|}
\hline $\mathbf{N}^{\circ}$ & \multicolumn{1}{|c|}{ Editoras } & $\begin{array}{c}\text { Contagem } \\
\text { dos Titulos }\end{array}$ & $\begin{array}{c}\text { Valor } \\
\text { Contratado }\end{array}$ & $\begin{array}{c}\text { Porcentage } \\
\text { m do valor } \\
\text { total }\end{array}$ \\
\hline 1 & $\begin{array}{l}\text { Ediouro Gráfica e Editora } \\
\text { Participações S/A }\end{array}$ & 1 & $210.299,67$ & $0,55 \%$ \\
\hline 2 & $\begin{array}{l}\text { Ediouro Publicações de } \\
\text { Passatempos e Multimídia LTDA }\end{array}$ & 1 & $251.787,36$ & $0,65 \%$ \\
\hline 3 & $\begin{array}{l}\text { Frase Efeito Estudio Editorial } \\
\text { LTDA }\end{array}$ & 1 & $290.413,83$ & $0,75 \%$ \\
\hline 4 & Editora Dimensão LTDA & 1 & $298.997,49$ & $0,78 \%$ \\
\hline 5 & Editora do Brasil S/A & 1 & $309.011,76$ & $0,80 \%$ \\
\hline 6 & Pia Sociedade de São Paulo & 1 & $336.193,35$ & $0,87 \%$ \\
\hline 7 & $\begin{array}{l}\text { Nova Amaérica Editora } \\
\text { Distribuidora de Livros LTDA }\end{array}$ & 1 & $353.360,67$ & $0,92 \%$ \\
\hline 8 & $\begin{array}{l}\text { Colégio Claretiano Assoc. Benef. } \\
\text { Ed }\end{array}$ & 1 & $387.695,31$ & $1,01 \%$ \\
\hline 9 & Editora Globo S/A & 1 & $389.125,92$ & $1,01 \%$ \\
\hline 10 & Editora Scipione S/A & 1 & $393.417,75$ & $1,02 \%$ \\
\hline 11 & Abril Educação S/A & 1 & $430.613,61$ & $1,12 \%$ \\
\hline 12 & Texto Editores LTDA & 1 & $436.336,05$ & $1,14 \%$ \\
\hline 13 & Martins Editora Livraria LTDA & 1 & $440.627,88$ & $1,15 \%$ \\
\hline 14 & Roda Viva Editora LTDA & 1 & $454.933,98$ & $1,18 \%$ \\
\hline 15 & Editora Lê LTDA & 1 & $456.364,59$ & $1,19 \%$ \\
\hline
\end{tabular}


Brandão, C.L.; Souza, R. J.

\begin{tabular}{|c|c|c|c|c|}
\hline 16 & Berlendis Editores LTDA & 1 & $459.225,81$ & $1,20 \%$ \\
\hline 17 & Editora Prumo LTDA & 1 & $460.656,42$ & $1,20 \%$ \\
\hline 18 & $\begin{array}{l}\text { Associacão Paranaense de } \\
\text { Cultura - APC } \\
\end{array}$ & 1 & $493.560,45$ & $1,29 \%$ \\
\hline 19 & $\begin{array}{l}\text { Elementar Publicações e Editora } \\
\text { LTDA }\end{array}$ & 1 & $510.727,77$ & $1,33 \%$ \\
\hline 20 & Richmond Educação LTDA & 1 & $517.880,82$ & $1,35 \%$ \\
\hline 21 & Callis Editora LTDA & 1 & $522.172,65$ & $1,36 \%$ \\
\hline 22 & Editora Biruta LTDA & 1 & $536.478,75$ & $1,40 \%$ \\
\hline 23 & $\begin{array}{l}\text { Editora Lendo e Aprendendo } \\
\text { LTDA }\end{array}$ & 1 & $543.631,80$ & $1,42 \%$ \\
\hline 24 & $\begin{array}{l}\text { DCL Difusão Cultural do Livro } \\
\text { LTDA }\end{array}$ & 1 & $610.870,47$ & $1,59 \%$ \\
\hline 25 & $\begin{array}{l}\text { SEFE - Sistema Educacional } \\
\text { Família e Escola LTDA }\end{array}$ & 1 & $619.454,13$ & $1,61 \%$ \\
\hline 26 & Comboio de Corda Editora LTDA & 1 & $662.372,43$ & $1,73 \%$ \\
\hline 27 & $\begin{array}{l}\text { Distr Record de Serv de } \\
\text { Imprensa SA }\end{array}$ & 1 & $670.956,09$ & $1,75 \%$ \\
\hline 28 & Editora Record LTDA & 1 & $670.956,09$ & $1,75 \%$ \\
\hline 29 & $\begin{array}{l}\text { Pia Sociedade Filhas de São } \\
\text { Paulo }\end{array}$ & 2 & $680.970,36$ & $1,78 \%$ \\
\hline 30 & Cata-Sonho Editora LTDA & 1 & $711.013,17$ & $1,85 \%$ \\
\hline 31 & $\begin{array}{l}\text { Casa da Palavra Producao } \\
\text { Editorial LTDA }\end{array}$ & 2 & $776.821,23$ & $2,03 \%$ \\
\hline 32 & JPA LTDA & 2 & $783.974,28$ & $2,04 \%$ \\
\hline 33 & $\begin{array}{l}\text { Livraria Martins Fontes Editora } \\
\text { LTDA }\end{array}$ & 2 & $789.696,72$ & $2,06 \%$ \\
\hline 34 & Nobel Franquias & 1 & $808.294,65$ & $2,11 \%$ \\
\hline 35 & Edições SM LTDA & 2 & $824.031,36$ & $2,15 \%$ \\
\hline 36 & Gráfica e Editora Anglo LTDA & 1 & $832.615,02$ & $2,17 \%$ \\
\hline 37 & Editora Gaia LTDA & 2 & $932.757,72$ & $2,43 \%$ \\
\hline 38 & Autêntica Editora LTDA & 2 & $934.188,33$ & $2,44 \%$ \\
\hline 39 & Editora Moderna LTDA & 2 & $942.771,99$ & $2,46 \%$ \\
\hline 40 & $\begin{array}{l}\text { Editora Gutenberg Comércio e } \\
\text { Representacões LTDA }\end{array}$ & 2 & $974.245,41$ & $2,54 \%$ \\
\hline 41 & Editora Globo Livros LTDA & 2 & 999.996,39 & $2,61 \%$ \\
\hline 42 & Editora Ática S/A & 2 & $1.045 .775,91$ & $2,73 \%$ \\
\hline 43 & Salamandra Editorial LTDA & 2 & $1.092 .986,04$ & $2,85 \%$ \\
\hline 44 & Empresa Folha da Manhã S/A & 2 & $1.115 .875,80$ & $2,91 \%$ \\
\hline 45 & RHJ Livros LTDA & 2 & $1.123 .028,85$ & $2,93 \%$ \\
\hline 46 & $\begin{array}{l}\text { Manati Produções Editoriais } \\
\text { LTDA }\end{array}$ & 2 & $1.181 .683,86$ & $3,08 \%$ \\
\hline 47 & $\begin{array}{l}\text { Editora WMF Martins Fontes } \\
\text { LTDA }\end{array}$ & 2 & $1.263 .228,63$ & $3,30 \%$ \\
\hline 48 & Editora Projeto LTDA & 2 & $1.400 .567,19$ & $3,66 \%$ \\
\hline
\end{tabular}


Brandão, C.L.; Souza, R. J.

\begin{tabular}{|c|l|c|c|c|}
\hline 49 & Editora FTD SA & 2 & $1.466 .375,25$ & $3,83 \%$ \\
\hline 50 & Editora Schwarcz LTDA & 2 & $1.543 .628,19$ & $4,03 \%$ \\
\hline 51 & Brinque Book Editora de Livros & 3 & $1.606 .575,03$ & $4,20 \%$ \\
\hline 52 & Cosac \& Naify Edicões LTDA & 3 & $1.702 .425,90$ & $4,45 \%$ \\
\hline & Total Geral & $\mathbf{7 5}$ & $\mathbf{3 8 . 2 5 1 . 6 5 0 , 1}$ & $\mathbf{8}$ \\
\end{tabular}

Fonte: Elaborado com dados de Brasil (2016b)

Os programas governamentais nas aquisições de obras de literatura causam um impacto nas produções das editoras. Rocha e Machado (2011, p. 70), ao discutir essa relação, pontuam que "o Brasil vem tendo, continuadamente, grandes programas de compras de livros pelo governo, para escolas e bibliotecas, o que o torna um campeão mundial nessa área". Ademais, existe uma demanda por livros produzidos especificamente para os programas, pois as editoras encomendam obras para serem inclusas no processo de seleção, pois alguns títulos pertencentes ao PNLD-PNAIC 2013 não são encontrados em livrarias.

Importante, destacar, ainda que, o processo de negociação dos valores de cada título dependem, diretamente, do número de tiragens que são adquiridas. Ao ponderarmos os dados dos valores das obras do PNBE 2012 com o PNLD - PNAIC 2013, percebemos uma diferença expressiva na negociação entre editoras e governo. O Quadro 3 aponta as quantidades de exemplares adquiridos em cada categoria do PNBE 2012 e PNLD - PNAIC 2013.

Quadro 3. Quantidade de exemplares para o PNBE (2012) e PNLD - PNAIC (2013)

\begin{tabular}{|l|c|c|}
\hline \multicolumn{1}{|c|}{ Programas } & $\begin{array}{c}\text { Quantitativo de } \\
\text { exemplares } \\
\text { adquiridos }\end{array}$ & $\begin{array}{c}\text { Quantitativo de } \\
\text { aquisição para o } \\
\text { Programa }\end{array}$ \\
\hline PNBE 2012 - Creche & 19.094 & 953.700 \\
\hline PNBE 2012 - Pré-Escola & 50.610 & 2.530 .500 \\
\hline $\begin{array}{l}\text { PNBE 2012 - Anos Iniciais } \\
\text { (E.F) }\end{array}$ & 55.744 & 5.574 .400 \\
\hline PNBE 2012 - EJA & 29.097 & 1.425 .753 \\
\hline PNLD - PNAIC 2013 & 143.061 & 10.729 .575 \\
\hline
\end{tabular}

Fonte: Elaborado com dados de Brasil (2016a, 2016b) 
O número de exemplares adquiridos pelo PNLD - PNAIC foi bem maior do que a tiragem dos acervos do PNBE 2012, esse fato fez com que a negociação do valor de compra de cada obra fosse relativamente diferenciada em relação ao valor de compra pelo PNBE 2012, já que o quantitativo de exemplares interferiu significativamente no valor de comercialização entre Governo Federal e editoras.

Nessa direção, Cosson e Paiva (2014) afirmam que, como se trata de uma compra volumosa, o ganho em escala e a eliminação de intermediários levam o preço individual do livro a patamares muito mais baixos do que aqueles encontrados em livrarias. O Quadro 4 apresenta os valores de negociação de alguns títulos.

Quadro 4. Valores de títulos adquiridos pelo PNBE 2012 e PNLD-PNAIC 2013

\begin{tabular}{|l|c|c|c|}
\hline \multirow{2}{*}{ Títulos } & \multicolumn{2}{|c|}{ Valor de aquisição para o MEC } & Valor de venda \\
\cline { 2 - 4 } & PNBE 2012 & $\begin{array}{c}\text { PNLD - PNAIC } \\
\mathbf{2 0 1 3}\end{array}$ & $\mathrm{R} \$ 23,90$ \\
\hline A árvore generosa & 3,91 & 2,68 & $\mathrm{R} \$ 28,20$ \\
\hline $\begin{array}{l}\text { As princesas soltam } \\
\text { pum }\end{array}$ & 4,85 & 3,61 & $\mathrm{R} \$ 42,00$ \\
\hline A lua dentro do coco & 7,48 & 5,18 & \\
\hline
\end{tabular}

Fonte: Elaborado com dados de Brasil (2016a, 2016b) e Livraria Saraiva ${ }^{3}$

Percebemos que as altas tiragens das obras adquiridas pelos programas influenciam diretamente nos valores de compra, com os dados do quadro 4 verificamos que o PNLD - PNAIC 2013 adquiriu os títulos por valores menores que o da aquisição do PNBE 2012 e, ainda, se compararmos com os valores de venda encontrados nas livrarias notamos uma diferença exorbitante, ou seja, o Governo Federal pagou a média de $12 \%$ do valor das obras vendidas no comércio de livros. Essas constatações provoca-nos a entender a reflexão de Rocha e Machado (2011, p. 69) quando assinalam que os livros talvez sejam caros para o bolso do povo e que temos que considerar que o que barateia as obras são as grandes tiragens e que "se muita gente comprar, divide-se o custo

\footnotetext{
${ }^{3}$ Valor retirado do site da Livraria Saraiva. Disponível em: <http://www.saraiva.com.br>. Acesso em 21 de junho de 2017.
} 
Brandão, C.L.; Souza, R. J.

por muitos exemplares e cada exemplar vai custar menos. Nossas tiragens são muito pequenas, ínfimas. Assim, fica difícil reduzir o custo unitário para baratear o livro".

Dessa ótica, ressaltamos que além das distribuições de livros pelo Governo Federal, as famílias e as instituições escolares deveriam ter condições de adquirirem por meio de compras obras literárias para a constituição de acervos pessoais e individuais. No entanto, ficam as indagações: Será que a maioria das famílias brasileiras podem ter o luxo de comprar um livro de literatura? Será que é prioridade das escolas a aquisição de materiais de leitura para suas/es alunas/os e professoras/es?

\section{As Obras do PNLD - PNAIC 2013 Chegaram, e Agora?}

Iniciamos a discussão com um diálogo sobre as possibilidades de utilização das obras literárias do PNLD-PNAIC 2013 resaltando a importância do conhecimento dos 75 títulos pelos profissionais da educação (professores e bibliotecários). Em suma, os livros também contribuem para a formação do professor/a enquanto leitor/a de literatura. Em relação ao repertório de leitura literária Abramovich comenta que as/os professoras/es trabalham

[...] com um leque muito estreito de alternativas... Conhece pouco de literatura infantil, em geral aqueles livros que as editoras enviam para sua casa/escola ou aqueles cujos autores estão mais dispostos a divulgar seus trabalho... ( e fica difícil achar que, por um desses dois métodos, realmente se chegue a acompanhar o que é publicado de relevante, de significativo, de bom...). (ABRAMOVICH, 1997, p. 140).

Complementarmente, também temos a pesquisa de Girotto e Souza (2010) demonstrando que docentes e bibliotecários conhecem poucos dos livros de literatura infantil, bem como os autores e ilustradores. Diante disso, podemos dizer que distribuição de obras literárias pelo PNLDPNAIC 2013 possuem a dupla função de promover o aumento do repertório de leituras das/os professoras/es e das crianças. 
Nesta perspectiva, para o trabalho com as obras em sala de aula, primeiramente, é necessário que os docentes conheçam as histórias que serão apresentadas. Em consonância com isso, Faria (2013, p. 14) assinala que "o professor, para elaborar seu trabalho com a leitura de livros para as crianças, precisa ler primeiro essas obras como leitor comum, deixando-se levar espontaneamente pelo texto, sem pensar ainda na sua utilização em sala de aula.

Por conseguinte, se os acervos foram entregues para ficarem nas salas de aula, a/o professora/or será a/o mediadora/or entre crianças e livros, organizando o seu trabalho com situações que permitam o uso das obras. Anteriormente, já explicamos que o PNLD-PNAIC está articulado com a formação das alfabetizadoras e o programa incentivou a inclusão da prática da leitura deleite no planejamento pedagógico.

Com isso, o documento do PNAIC conceitua que a leitura deleite "é ler para se divertir, sentir prazer, para refletir sobre a vida. Tal prática, no entanto, não exclui as situações de conversa sobre os textos, pois esse momento também é de prazer, além de ser de ampliação de saberes" (BRASIL, 2012, p. 29). Diante disso, temos a afirmação de Balsan e Debus:

Cabe ao educador então, ler e contar histórias para as crianças, com frequência, uma vez que, as histórias da tradição oral, crônicas, contos - incluindo os de fada, são motivos de prazer para elas; e ao mesmo tempo ampliam a visão de mundo, representando simbolicamente problemas humanos [...]. ( DEBUS; BALSAN, 2016, p. 160).

O convivio com narrativas literárias, seja pelo ato de ler ou de contar, é uma ação pedagógica que também promove o interesse pelo desenvolvimento das práticas de leitura. Bedran aponta que:

As experiências através das narrativas são fundamentais para a formação de leitores, pois todo ouvinte de uma boa história que lhe toca profundamente a alma faz uma corrida em direção aos livros, sedento de reencontrar neles impressos o sonho, a emoção e o afeto vivenciados anteriormente durante o "narrarouvir-criar". (BEDRAN, 2012, p. 110). 
Brandão, C.L.; Souza, R. J.

É pertinente, mesmo que de forma sucinta, situar que o ato de ler é diferente do ato de contar, pois a contação exige um desligamento do narrador com o texto impresso. Sisto e Motoyama (2016, p. 113) esclarecem que "contar é se expor, é virar foco de atenção, é ter que cuidar da performance, é despir-se do papel conhecido (muitas vezes de professor!) para assumir o papel de artista." No entanto, precisamos considerar que o momento de ler e contar uma história não pode ser realizado de qualquer jeito, deve ser uma situação planejada e as/os professoras/es precisam demonstrar familiaridade com o texto.

Ao pensarmos, então, em tal planejamento além do ato de ler e contar, é pertinente inserirmos algumas metodologias como: 1) Formação de um espaço de leitura para disponibilização do livros e 2) uso das estratégias de leituras.

No primeiro momento, a formação de um espaço de leitura organizado para que as crianças possam procurar livros que the chamem atenção ou suas obras preferidas para a realização da leitura individual ou até mesmo para que elas possam ser os mediadores do ato de ler ou contar para seus colegas. Segundo Debus e Balsan é

[...] por meio da contação de histórias e da leitura mediadora da atividade literária que a criança poderá desenvolver esse prazer pela leitura que motivará o leitor iniciante a construir a leitura, não como atividade com vistas a uma "recompensa" ou " castigo", mas sim como uma prática cultural e uma capacidade especificamente humana transformadora da realidade. (DEBUS; BALSAN, 2016, p. 165).

No segundo, as estratégias de leituras são propostas por Solé (1998) como procedimentos que devem ser ensinados para a compreensão de textos. Girotto e Souza (2010, p. 54) explicam que as estratégias de leituras são [...] mecanismos individuais que o leitor desenvolve ao longo de sua vida, para obter uma informação por meio do ato de ler". As estratégias estão categorizadas em conexões: a) texto-leitor: estabelece relações do texto lido algo ocorrido em sua vida; b) texto-texto: relaciona o texto lido com outro texto (intertextualidade); c) texto-mundo: conecta o texto lido com algum acontecimento no mundo. 
Brandão, C.L.; Souza, R. J.

O trabalho com as obras podem partir de várias situações como: levar as crianças a conhecerem o livros a partir do seu texto e paratextos, explorar as relações entre texto e ilustrações, aumentar o vocabulário e o repertório das histórias. Todas esses itens são necessários para a constituição dos alunos como sujeitos leitores.

\title{
Algumas Palavras para não Finalizar
}

\begin{abstract}
Ah, como é importante para a formação de qualquer criança ouvir muitas histórias e muitas histórias... Escutá-las é o início da aprendizagem para ser um leitor, e ser leitor é ter um caminho absolutamente infinito de descoberta e de compreensão do mundo... (ABRAMOVICH, 1997, p. 16).
\end{abstract}

Nos limites deste texto, tivemos como objetivo principal compreender as ações do PNLD-PNAIC 2013 a partir de reflexões sobre a importância da presença da literatura nas salas de alfabetização sempre pensando na oferta e no acesso a obras literárias para as crianças do $1^{\circ}$ ao $3^{\circ}$ ano.

Nessa investigação, avaliamos a distribuição do PNDL-PNAIC 2013 como uma ação importante para prover o acesso de obras de literatura infantil para as crianças nas salas de alfabetização. Análise que corrobora com Rocha e Machado (2011, p. 65) quando avaliam que as escolas recebem livros de qualidade e "pode ser que alguns não tenham tanta qualidade assim, pode haver um ou outro programa que não seja tão bom, mas em sua maioria, é fruto da seleção de várias cabeças. Não são livros impostos ou impingidos por alguém”.

Entretanto, ao nos referirmos sobre o PNDL-PNAIC 2013, ainda será necessário que os proponentes dessa política entendam que além da distribuição é necessário a promoção contínua de formação das/os mediadoras/es para que o uso das obras literárias sejam significativo para as práticas de leitura.

Assim, compreendemos que as discussões apresentadas neste texto são possiveis de serem aprofundadas, a fim de ajudar no trabalho da leitura e literatura nas escolas, no entanto, ressaltamos novamente a 
Brandão, C.L.; Souza, R. J.

importância da chegada desses livros nas instituições escolares pela promoção do contato das/os professoras/es e alunas/os com a leitura literária.

\section{Referências}

ABRAMOVICH, Fanny. Literatura Infantil: gostosuras e bobices. São Paulo: Scipione, 1997.

ARENA, Dagoberto Buim. A literatura infantil como produção cultural e como instrumento de iniciação da criança no mundo da cultura escrita. In: SOUZA, Renata Junqueira de et al. Ler e compreender: estratégias de leitura. Campinas, SP: Mercado de Letras, 2010. p. 13- 44.

BAJARD, Élie. A sessão de mediação: Um dispositivo engenhoso. In: BAJARD, Élie. Da escuta de textos à leitura. 2. ed. São Paulo: Editora Cortez, 2014. p. 43-66.

BEDRAN, Bia. A arte de cantar e contar histórias: narrativas orais e processos criativos. Rio de Janeiro: Nova Fronteira, 2012.

BRANDÃO, Claudia Leite. PNBE do Professor: Usos e desusos. 2016. Dissertação (Mestrado em Educação) - Universidade Federal de Mato Grosso, Rondonópolis, 2016.

BRASIL. Ministério da Educação. Secretaria de Educação Básica. Formação de Professores no Pacto Nacional pela Alfabetização na Idade Certa. Brasília: MEC/SEB, 2012.

BRASIL. Secretaria de Educação Básica. PNBE 2012 títulos e valores. Disponivel em: <http://www.fnde.gov.br/programas/biblioteca-daescola/biblioteca-da-escola-dados- estatisticos/item/3016-dadosestat\%C3\%ADsticos-de-anos-anteriores>. Acesso em: 20 jan. 2016a.

BRASIL. Secretaria de Educação Básica. Dados estatísticos do PNAIC 2013. Disponivel em: <http://www.abrelivros.org.br/home/images/ dados_estatisticos_pnaic_2013.pdf>. Acesso em: 8 fev. 2016b.

COSSON, Rildo; PAIVA, Aparecida. O PNBE, a literatura e o endereçamento escolar. Remate de Males, Campinas, v. 34, n. 2, p. 477499, jul./dez. 2014.

DEBUS, E.; BALSAN, S. F.S. Os recursos para o contar histórias... das tramas que o entretecem. In: GIROTTO, C. G. G. S.; SOUZA, R. J. Literatura e Educação Infantil: livros, imagens e práticas de leitura. Campinas: Mercado de Letras, 2016. p. 153-172.

FARIA, Maria Alice. Como usar a literatura infantil na sala de aula. 5. ed. São Paulo: Contexto, 2013. 
GIROTTO, C.G.G.S.; SOUZA, R.J. Estratégias de leitura: para ensinar alunos a compreender o que leem. In: SOUZA, R.J. (Org.). Ler e compreender: estratégias de leitura. Campinas: Mercado de Letras, 2010.

PAIVA, Aparecida; CORREAA, Hércules Tolêdo. Literatura \& Alfabetização: impasses e possibilidades. Via Atlântica, São Paulo, n. 28, p. 177-196, dez. 2015.

ROCHA, Ruth; MACHADO, Ana Maria. Contando histórias, formando leitores. Campinas, SP: Papirus 7 Mares, 2011.

SILVA, Roseane P. Leitura e escrita na alfabetização. In: MORAIS, A. G.; ALBUQUERQUE, E. B. C.; LEAL, T. F. (Org.). Alfabetização: apropriação do sistema de escrita alfabética. Belo Horizonte: Autêntica, 2005.

SISTO, C.; MOTOYAMA, J. A narração de histórias na infância: técnicas e interação. In: GIROTTO, C. G. G. S.; SOUZA, R. J. Literatura e Educação Infantil: livros, imagens e práticas de leitura. Campinas: Mercado de Letras, 2016. p. 111-138.

SOARES, Magda B. Alfabetização e Literatura. Revista Educação. Guia da Alfabetização, São Paulo, Publicação Especial, n. 2, p. 12-29. 2010.

SOLÉ, Isabel. Estratégias de leitura. Tradução: Cláudia Schilling. Porto Alegre: Artmed, 1998.

SOUZA, Renata J.; SILVA, Kenia Adriana de A. M.; ARIOSI, Cinthia M. F. A Leitura e a Função da Literatura no PNAIC: para Além do Deleite. Educação em Revista, Marília, v.17, Edição Especial, p. 63-80, 2016. 